\title{
EL COLEGIO DE SAN PABLO EN GRANADA: DE ESCUELA JESUITA A UNIVERSIDAD (1556-1769)
}

\author{
MARÍA DEL CARMEN VÍLCHEZ LARA ${ }^{1}$ \\ Universidad de Granada
}

\begin{abstract}
El Colegio de San Pablo de Granada, una de las fundaciones más relevantes de los jesuitas en España, es objeto, en este trabajo, de un exhaustivo análisis de las fuentes documentales, a la par que se hace una revisión crítica de las investigaciones realizadas sobre el edificio. Todo ello permite elaborar un preciso recorrido de las etapas de su construcción y levantar una planimetría que ilustre este complejo proceso. Esta planimetría es clave para analizar el variable uso de sus espacios a lo largo del Antiguo Régimen.
\end{abstract}

Palabras clave: Jesuitas; Colegio de San Pablo; Granada; Arquitectura; Universidad.

THE COLLEGE OF ST PAUL IN GRANADA: FROM JESUIT SCHOOL TO UNIVERSITY (1556-1769)

The College of St Paul in Granada, one of the most important foundations of the Jesuits in Spain, is here the object of an exhaustive analysis of the documentary sources, as well as a critical review of the research carried out on the building. This information permits the elaboration of a precise path for the stages of its construction and the creation of mapping to illustrate this complex process. This mapping is key to analyzing the variable uses of these spaces during the Old Regime.

Key words: Jesuits; College of St Paul; Granada; Architecture; University.

Cómo citar este artículo / Citation: Vílchez Lara, María del Carmen (2017): "El Colegio de San Pablo en Granada: de escuela jesuita a universidad (1556-1769)". En: Archivo Español de Arte, vol. 90, núm. 360, Madrid, pp. 347-364. doi: 10.3989/aearte.2017.23

\section{Colegio de San Pablo: cronología de su levantamiento}

La implantación conventual en Granada, tras su conquista por los Reyes Católicos, será decisiva dentro del proceso de transformación de la ciudad islámica, definida por sus minaretes y murallas, en la sacralizada ciudad cristiana del Antiguo Régimen. Mientras las iglesias parroquia-

1 mariacarmenvl@ugr.es / ORCID iD: http://orcid.org/0000-0002-0832-9439.

2 Durante el desarrollo de este trabajo de investigación, motivado inicialmente por la carencia de una documentación gráfica que ayudase a comprender las fases constructivas del Colegio de San Pablo, se fueron detectando errores de importancia en recientes publicaciones consultadas sobre este tema. Entre otros, Córdoba Salmerón cita en su tesis que el plano más antiguo del Colegio conservado en el Archivo Histórico Nacional (AHN) lo realizó el hermano Martín de Baseta en 1575 (Córdoba Salmerón, 2005: 89-90). Aunque es probable que Baseta trazase un plano antes de empezar a ejecutarse la iglesia en 1574, el plano del AHN correspondiente a este autor es de 1597. En cuanto a la datación de la escasa planimetría histórica existente, mayor es el error en el que incurre Ramírez Molina, 2012: 13, al considerar que las dos plantas históricas del Colegio fueron realizadas en 1579, asignando la de 1597 como planta baja 
les del clero secular se limitaron a convertir los alminares en campanarios y las mezquitas en iglesias, sin suponer un gran cambio en la fisonomía urbana, el establecimiento de un gran número de órdenes religiosas en la ciudad será el detonante de la ruptura con la ciudad musulmana. El impacto urbano de los conventos y monasterios levantados por el clero regular, que se iban instalando tanto en la periferia como en el centro de la ciudad, supuso un "cambio profundo, pues no había nada que se pareciera a ellos en la Granada islámica". Los cenobios se erigieron "donde antes había casas o fincas sin urbanizar subvirtiendo lo que había al introducir esa mezcla de espacio público (el templo) y reservado (casa conventual)"3. A mediados del siglo XVI, la urbe granadina se había convertido en una ciudad fuertemente sacralizada, con doce conventos masculinos y once femeninos, además de la Catedral, las iglesias parroquiales e innumerables cruces y hornacinas esparcidas por todos los barrios.

Los jesuitas se instalan en Granada en 1554 gracias al decidido apoyo del arzobispo Pedro Guerrero, quién les facilitará el dinero para el alquiler de las casas donde se van alojando e incluso para la adquisición de solares donde levantar de nueva planta el colegio e iglesia de la Compañía ${ }^{4}$.

\section{La primera residencia: el cuarto viejo trazado por el padre Bartolomé de Bustamante}

En abril de 1556 se compraron los primeros solares, situados en la calle San Jerónimo, junto a la muralla. El padre Bartolomé de Bustamante (1501-1570), uno de los primeros jesuitas redactores de las normas que debían seguir en cuanto a su trazado las iglesias y colegios de la Compañía, fue el encargado de realizar el diseño de la primera residencia jesuita granadina en agosto de $1556^{5}$. Al mes siguiente, dieron comienzo las obras de apertura de zanjas para la cimentación del que sería conocido como cuarto viejo, aunque la adquisición oficial de estos terrenos no tendría lugar hasta meses más tarde, en abril de 1557. Para ello, fue necesario comprar las casas contiguas al primer solar y hubo que solicitar al cabildo parte de la muralla, con su torreón y barbacana incluidos, pues estos se hallaban en mitad de la parcela:

"Se comenzaron a comprar algunas casillas que en la calle de San Hiéronimo había, donde se comenzó el nuevo edificio [...] También se pidió al Cabildo de la Ciudad nos hiciese merced de un pedazo grande de muralla y barbacana y una torre muy grande que atravesaba por medio nuestro sitio"6. La muralla y barbacana que cruzaba el solar jesuita formaba parte del amurallamiento de la parte oeste de la Medina de Granada (Madinat Garnata), representado por Orihuela Uzal y García Pulido en el Trazado hipotético de las murallas de la Granada islámica ${ }^{7}$ La gran torre a la que se refiere la Historia del Colegio de San Pablo es la Puerta del Molino (Bab al-Riha), que Gómez-Moreno denomina, en su Guía de Granada, Puerta de San Jerónimo y la sitúa bajo la capilla mayor de la iglesia del Colegio ${ }^{8}$.

El cuarto viejo, inaugurado el 25 de enero, festividad de la conversión del apóstol San Pablo, de 1562 por el vicerrector Alonso Ruiz, constaba de dos plantas de altura e incluía los aposentos de invierno y de verano, las clases de estudios mayores, las dependencias comunes como refectorio, cocina, despensa, enfermería, y una pequeña capilla en planta baja ${ }^{9}$; una construcción en

\footnotetext{
y la de 1579 como planta alta. Sin embargo, hay que reconocer que el trabajo de Ramírez es espléndido en cuanto al análisis estructural de la cúpula de la Iglesia, aunque no en lo relativo a la historia del Colegio.

3 Barrios Rozúa, 2004: 641-642.

4 Gómez-Moreno Calera, 1989: 192. Barrios Rozúa, 2014: 209.

5 Rodríguez Gutiérrez de Ceballos, 2004: 64-65.

6 Béthencourt/Olivares, 1991: 31.

7 Orihuela Uzal, 2001.

${ }^{8}$ Gómez-Moreno González, 1998: 384.

9 La capilla dejó de utilizarse como tal en 1589, cuando se inauguró la iglesia, una vez concluido el cuerpo principal y la capilla mayor levantada hasta la cornisa. Béthencourt/Olivares, 1991: 182. El cuarto viejo tenía capacidad para 60 individuos. Rodríguez Gutiérrez de Ceballos, 1967: 165.
} 


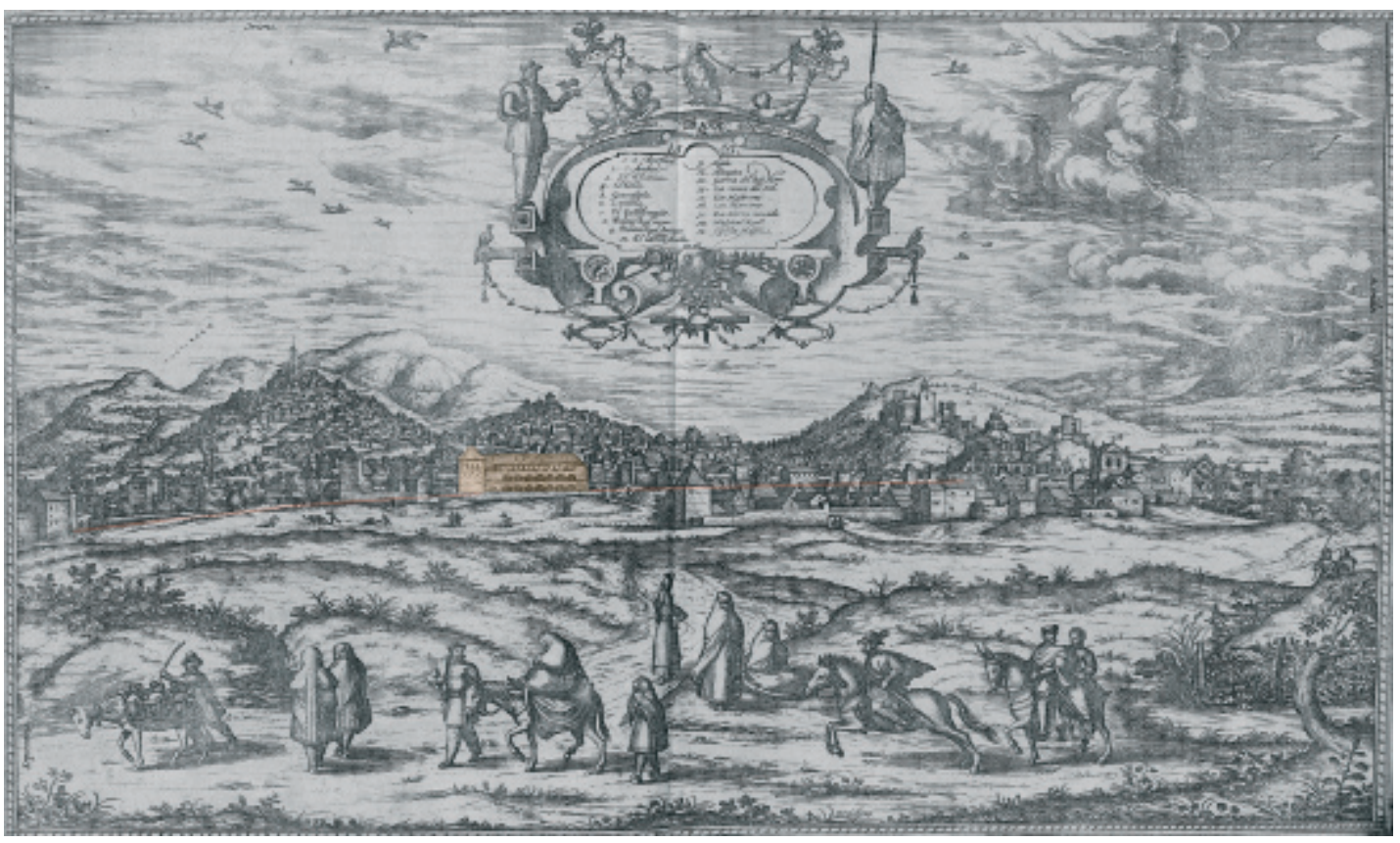

Fig. 1. Cuarto viejo del Colegio de San Pablo en la calle San Jerónimo, sobre Joris Hoefnagel, vista de Granada desde poniente, dibujada entre 1563 y 1565 y publicada en el Civitates orbis terrarum: liber primus en 1576 .

la que primaron los criterios jesuíticos de funcionalidad, comodidad y capacidad, siguiendo los preceptos que, según la primera congregación general de los jesuitas, celebrada en 1558, debían cumplir los edificios de la Compañía: sencillos, salubres y adaptados al fin para el cual eran construidos, exentos de lujo y refinamiento ${ }^{10}$. Aunque no se ha podido encontrar el plano que el padre Bustamante debió trazar para el cuarto viejo del Colegio de San Pablo, sabemos que esta planta fue imitada en otros colegios de la Compañía, incluso años más tarde, como es el caso de Écija o Guadix ${ }^{11}$. El alzado hacia la vega, con su logia doble, fue dibujado por Joris Hoefnagel hacia 1565 (fig. 1).

La siguiente imagen en la que aparece representado en perspectiva el colegio jesuita, es obra de Anton van den Wyngaerde, pintor y cartógrafo flamenco que recibe el encargo de dibujar vistas topográficas de las principales ciudades españolas. A diferencia del Civitates orbis terrarum, que parte de una iniciativa editorial privada, en la que Hoefnagel introduce elementos pintorescos de la vida cotidiana, Wyngaerde fue contratado por Felipe II para el trazado de las cartografías urbanas, con criterios topográficos, en los que la figura humana está representada a la misma escala que los edificios ${ }^{12}$. El levantamiento urbano de Granada es realizado en 1567 desde el suroeste, quedando en primer plano el eje de la calle San Jerónimo, que partiendo del costado de la Catedral conducía hasta el monasterio del mismo nombre. Esta vía se convirtió en "eje ritual de la Granada renacentista", en la que además de asentarse numerosas órdenes contrarreformistas, se configuró una arquitectura residencial nobiliaria ligada siempre a un jardín o huerta ${ }^{13}$. El cuarto viejo del Colegio de San Pablo es dibujado con minuciosidad, destacando su doble cuerpo de arquerías, con algunos arcos cegados en planta baja. Junto a él, el palacio de los

\footnotetext{
10 Wittkower/Jaffe, 1992.

11 Rodríguez Gutiérrez de Ceballos, 1967: 164.

12 Vistas de Granada en Kagan, 1986: 266-273. Calatrava Escobar/Ruiz Morales, 2005: 45-47.

13 Acale Sánchez, 2005: 36-37. Gila Medina, 2015: 36.
} 

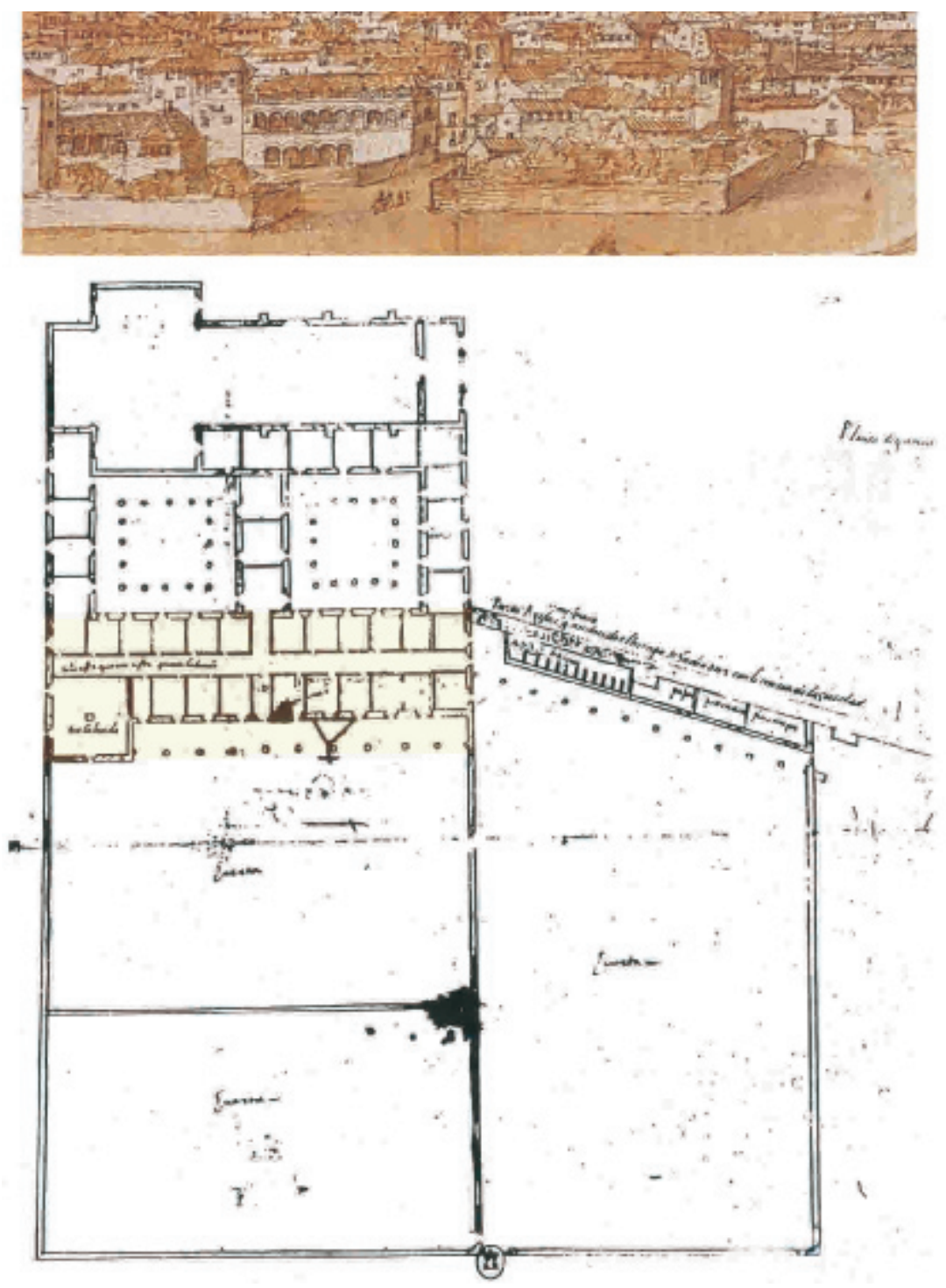

Fig. 2. Cuarto viejo del Colegio de San Pablo. Sup.: perspectiva de Anton van den Wyngaerde, fragmento de Granada, vista de 1567, publicada en Kagan, 1986. Inf.: Cuarto viejo indicado sobre Giuseppe Valeriani, planta del Colegio de San Pablo, Granada, 1579. Béthencourt/ Olivares, 1991.

Beneroso y detrás, el convento de la Encarnación (fig. 2 sup.). A finales de 1569 se adquirió la huerta situada detrás de la muralla, en el lugar donde más adelante se levantarán las escuelas.

El plano que trazó el padre Giuseppe Valeriani (1542-1596) en 1579, tras su visita de inspección al colegio granadino, puede también darnos una clara idea de cómo sería la disposición del cuarto viejo. Era la única parte que ya estaba totalmente construida dentro del proyecto que realiza Valeriani para enviar a Roma, junto con su negativo informe sobre las obras que se estaban ejecutando para la iglesia, iniciada en 1574, bajo la dirección de Lázaro de Velasco y Martín de Baseta ${ }^{14}$. En dicho informe indicó varios fallos, entre ellos el de la orientación, imposible ya de remediar; el de la firmeza, consideraba insuficientes los muros levantados para soportar las cargas, afirmando que se terminarían abriendo; y, finalmente, el de la falta de gracia en el diseño. Valeriani no se limitó a proyectar una nueva planta para la iglesia, sino que dibujó también el cuarto viejo existente y dos patios iguales situados entre la iglesia y la vivienda (fig. 2 inf.). En

\footnotetext{
14 Béthencourt/Olivares, 1991: 36.
} 
Fig. 3. Análisis tipológico, funcional y morfológico, a través de los vacíos generadores y organizadores de los espacios construidos, sobre el proyecto de

Martín de Baseta, planta del Colegio de San Pablo, Granada,

1597. Plano base

para el análisis en Béthencourt/Olivares, 1991.

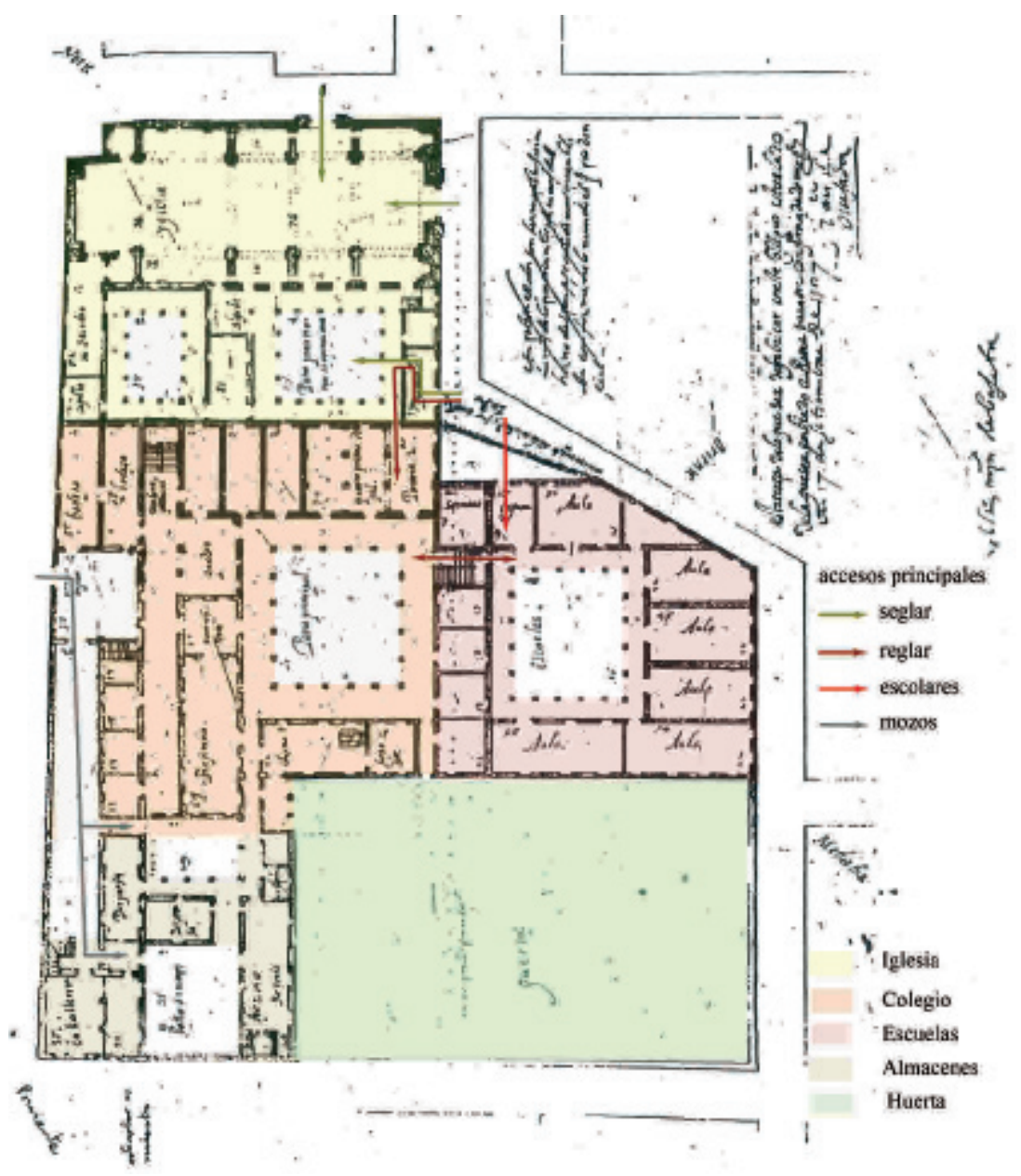

cuanto Valeriani se marchó de Granada, Velasco y Baseta continuaron ejecutando su proyecto de iglesia con capillas laterales.

\section{Análisis de la tipología del Colegio jesuita a través del proyecto del hermano Martín de Baseta}

En 1597, finalizadas gran parte de las obras de la iglesia, se le encarga al hermano Martín de Baseta (1527-1604) trazar la ampliación del colegio jesuita, reducido aún al pabellón diseñado por Bustamante, y las escuelas ${ }^{15}$. En este plano de planta baja podemos distinguir claramente las tres zonas proyectadas para el buen funcionamiento del colegio: la residencia, las escuelas y la iglesia. A éstas hay que sumarle una cuarta pieza, de menor valor constructivo, donde se alojan las dependencias secundarias destinadas a almacenes y caballerizas (fig. 3).

La nueva vivienda de los jesuitas se organizaba alrededor de un patio o claustro principal, al norte del cual quedaría el cuarto viejo, sobre el que Martín de Baseta propone cambios en su

15 En las tres capillas del lado del evangelio se instalaron provisionalmente las aulas del colegio "separadas de la nave por unos tabiques, y abierta una comunicación con la explanada" del patio de seglares. Rodríguez Gutiérrez de Ceballos, 1967: 183-184. 
distribución. El ala oeste alojaría las oficinas y el refectorio; el pabellón sur, una capilla, que serviría también de teatro de conclusiones; mientras que la crujía este, en contacto con las escuelas, sería destinada a aposentos de verano. Aunque no existe plano de planta alta, sabemos que en ella estarían las celdas de los religiosos. A las escuelas podría accederse o bien directamente desde la calle o a través de la comunicación abierta con la casa jesuita, tras subir unos peldaños que salvaban la diferencia de cota del piso bajo. Se organizaban en torno a un patio central al que se abrían las seis aulas proyectadas. Con respecto al patio de separación de la iglesia con la casa jesuita, Martín de Baseta plantea dividirlo en dos para destinar el que queda junto a la portería de acceso, de mayor tamaño, a trato de seglares en las congregaciones religiosas ${ }^{16} \mathrm{y}$, separado por una crujía, un patio de menor tamaño abierto a la sacristía y a una pequeña capilla. La cuarta pieza, colocada en el ángulo oeste del solar, se estructuró en torno al patio llamado "de mozos", concibiéndose como un pabellón que debía diferenciarse del resto, mediante su construcción, con materiales más pobres y de una sola altura. Sería destinado a dependencias de servicios: caballerizas, despensas y horno.

Los planos realizados para el levantamiento de las construcciones jesuíticas sólo solían mostrar una planta general del edificio a ras de suelo, es decir, en planta baja, o en otras ocasiones se trataba de simples croquis de una parte del edificio. La explicación a esta escasez de planimetría se debe a la falta de normativa o reglamento que exigiera, para el estudio del proyecto en Roma, una documentación completa de plantas, alzados, secciones, perspectivas y detalles constructivos o decorativos. Según Vallery-Radot:

Théoriquement, le recueil devrait contenir, en proportion equivalente, des plans, des élévations et des dessins en perspective. En fait il n'en va pas ainsi. Les plans constituent l'immense majorité. Peu nombreuses sont les élévations et plus rares encore les dessins en perspective. Les coupes sont également exceptionnelles.

Cette répartition très inégale s'explique sans doute par le manque d'instructions prescrivant l'envoi de tels documents ${ }^{17}$.

Desde Roma, el padre General comprobaba que la distribución de los espacios fuese la correcta para el buen funcionamiento de los edificios, en cuanto a soleamiento, salubridad e higiene, y la posición de la iglesia en relación al entorno urbano. Del análisis de las plantas bajas de los colegios de la Compañía podemos deducir las características comunes que debían reunir todos ellos, compuestos principalmente por una iglesia y varios patios o claustros en torno a los cuales se organizaban la residencia, con los aposentos y espacios comunes de los religiosos; las escuelas, que debían incluir como mínimo las aulas, el teatro de actos públicos y la biblioteca; y los locales de servicios destinados a cocina, bodega, despensas, caballerizas, etc ${ }^{18}$. Junto a las edificaciones construidas es normal encontrar una huerta o jardín como lugar de recreo de profesores y alumnos, incluso en algunas ciudades se levantaba una casa de campo a las afueras de la ciudad ${ }^{19}$.

Las iglesias jesuíticas, generalmente ubicadas a un lado del solar, fueron levantadas y decoradas gracias a los donativos que realizaban sus fundadores y bienhechores a cambio de mostrar en ellas la importancia de su linaje, mediante la colocación de escudos de armas en las fachadas y la condición de ser enterrados en las capillas o criptas. Una parte de la dotación económica recibida era destinada a la construcción material o a la decoración de los colegios y templos y, otra parte, al sustento de los jesuitas que los habitaban. Los patios principales solían tener una disposición cuadrada y estar rodeados de pórticos, formados por arquerías sobre delgadas colum-

16 También denominado patio de confesores. Barrios Rozúa, 2006: 364.

17 Vallery-Radot/Lamalle, 1960: 19. Traducción: "Teóricamente, la colección debería contener, en proporción equivalente, plantas, alzados y dibujos en perspectiva. De hecho, no es así. Las plantas constituyen la inmensa mayoría. Poco numerosos son los alzados y más raros todavía los dibujos en perspectiva. Las secciones son también excepcionales. Este reparto muy desigual se explica sin duda por la falta de instrucciones que prescriban el envío de dichos documentos".

18 Patetta/Coscarella/Zocchi/Balestreri, 1990.

19 En Granada se construyó la casa jesuita de Jesús del Valle, junto al río Darro, en el camino de Beas. 
nas o machones. El patio adyacente al templo es con frecuencia denominado "patio para el trato de los prójimos", en torno al cual se situaban los aposentos de los jesuitas y otros espacios comunes. En el Colegio de San Pablo el cuarto viejo se dispuso paralelo al lugar donde se levantaría la iglesia, quedando entre ambos este patio, también llamado de trato de seglares. En las alas transversales a la iglesia se abrían la portería y otras salas de visita. El "patio de las escuelas" reunía las aulas a su alrededor, entre las que destacaba una clase más amplia o teatro para los actos públicos. Dependiendo del tamaño del colegio, en algunos podían existir más patios principales $^{20}$.

En 1601 dieron comienzo las obras de ampliación de la casa jesuita en Granada, levantándose el ala oeste del nuevo claustro principal, donde se ubicaron en planta baja el refectorio con su lavamanos y las oficinas, y el ala sur, con una gran estancia que servía a la vez de capilla y teatro. Se redistribuyó el cuarto viejo, según la propuesta de Martín de Baseta, una vez trasladados los aposentos de los jesuitas de la planta baja a la alta de la ampliación, demoliendo tabiques y levantando muros que delimitaron las aulas necesarias para las tres cátedras que se impartían desde finales del siglo XVI, en las capillas del lado del evangelio de la iglesia: lógica, filosofía y teología, origen de la Facultad de Teología granadina ${ }^{21}$. Se labró una vistosa galería, al tiempo que se construyó la casa de mozos para albergar las dependencias secundarias, de acceso directo desde la calle. En 1607 ya estaban concluidas todas estas obras habiéndose invertido en ellas una fuerte suma de dinero: "Acabose en este año el edificio que començó el P. Pedro Montes aviéndose gastado en él 20.500 ducados; donde fuera de la habitación para los nuestros se labraron officinas y bodegas y un refitorio muy capaz, y una sala grande que sirve de capilla y teatro para las conclusiones, y una vistosa galería, casa de mozos y portería seglar"22.

En la Plataforma de la ciudad de Granada de Ambrosio de Vico, dibujada en 1590 y grabada por Heylan en 1613, aún no aparecen las nuevas construcciones del colegio, ejecutadas de 1601 a 1607. Sin embargo, en ella encontramos la primera imagen de la iglesia jesuita, a falta de la cúpula y la torre, aún sin realizar. El cuarto viejo es representado muy simplificado, nada que ver con las arquerías mostradas en las dos vistas de Granada que le precedieron, la de Hoefnagel y la de Wyngaerde. Hacia 1630 se compró la casa que necesitaba el Colegio para completar la totalidad de la manzana en la que se ubicaba, "cosa que se deseaba años auía, porque solo este sitio faltaba para estar el Collegio en isla" 23 . De 1636 a 1638 se construye el pabellón este del patio de la casa, cerrándose por fin el claustro principal de la comunidad, para destinarlo a aposentos de verano. Seguidamente, el padre Gonzalo de Peralta decide acometer las obras de adecentamiento del patio situado entre la iglesia y la vivienda, destinado a trato de seglares devotos $^{24}$. En la Historia del Colegio de San Pablo se describe el lamentable estado en que dicho patio se hallaba: "Acomodose de prestado, quando se labró la iglesia, con unos colgadiços muy humildes, que eran [más terrados] que claustros de religión. Y estando a la primera vista y entrada de la casa desdecía mucho de la grandeza de ella, [...]. Era tan indigna esta primera entrada, que personas de mediano porte no se podían recibir allí” ${ }^{25}$.

A partir de aquí surgirán dos opiniones radicalmente distintas en cuanto a la forma que debía tener este patio y si debía ser dividido o no en dos. Como punto de partida, era condición indispensable no quitar luz a los aposentos del cuarto viejo. El padre Gonzalo de Peralta, rector del Colegio, defendía la delimitación de un único patio, de mayor longitud que anchura, entre la

20 Navarro Catalán, 2012: 59-61.

21 Martínez Medina, 2001: 82-83. Olivares, 1990.

22 Béthencourt/Olivares, 1991: 54.

23 Según la Historia del Colegio de San Pablo, esta casa se compró siendo rector el P. Jorge Hemelman, por lo que pudo ser de 1627 a 1630 o de 1633 a diciembre de 1635, aunque se pagó en 1638, siendo rector el P. Cristóbal de Cabrera. Béthencourt/Olivares, 1991: 89.

${ }^{24}$ Córdoba Salmerón atribuye la autoría de este patio al hermano Martín de Baseta en Córdoba Salmerón, 2005 : 95; 2006: 74, aunque se trata de un error, ya que correspondería al hermano Francisco Díaz del Ribero, como expongo más adelante. Baseta había fallecido en 1604.

${ }^{25}$ Béthencourt/Olivares, 1991: 91. 
portería y la sacristía, y adosar unas azoteas en los lados mayores del cuarto viejo y del templo, de manera similar al patio de la casa profesa de Sevilla ${ }^{26}$; mientras que el hermano arquitecto Francisco Díaz del Ribero (1595-1670) apostaba por dividir el patio en dos y, puesto que el primero de los patios sería el destinado al trato de seglares, deseaba añadirle vistosidad mediante la adición de cuatro corredores sustentados por arcos de medio punto sobre columnas toscanas. Sometidas ambas propuestas a votación, fue elegida la de Díaz del Ribero, comenzándose las obras en 1638 y concluyéndose en 1642. Recordemos que la propuesta de realizar dos claustros ya había sido llevada al plano tanto por Valeriani en 1579 como por Martín de Baseta en 1597. Díaz del Ribero utilizó para la decoración de las ventanas, arcos, frisos y cornisas del patio de seglares, grandes piezas de barro recortado que posteriormente cocía en el horno.

Las siguientes obras, ordenadas por el padre Hernando de Poblaciones, rector del Colegio de 1639 a 1642, correspondieron a la bodega y tonelera situadas en la parte posterior de la manzana, junto al estanque grande.

\section{El proyecto de las Escuelas del Colegio: el fundador padre Pedro de Fonseca versus el hermano arquitecto Francisco Díaz del Ribero}

La construcción de las escuelas tuvo que esperar hasta que los Fonseca, hermanos del padre Pedro de Fonseca, rector entre 1642 y 1646, legaran toda su fortuna, estimada en 33.000 ducados y varias propiedades, a la fundación de las escuelas del Colegio de San Pablo ${ }^{27}$. En la Historia del Origen y Fundación de la Universidad de Granada, Montells y Nadal nos narra las condiciones que pusieron los hermanos fundadores de las escuelas:

Todas estas posesiones las dejaron los referidos fundadores para que se hicieran las clases y teatro para los actos públicos de obra suntuosa, y á más de una magnífica portada en que se había de poner una imágen de Ntra. Señora de la Concepcion, delante de la cual había de encenderse una lámpara y pusieron por carga que se había de celebrar todos los años una solemnísima fiesta al misterio de la Concepcion [...] por memoria de la fundacion y sufragio de los fundadores, y á mas una fiesta a cada uno de los Santos de la Compañía conocidos hasta el año de $1640^{28}$.

El hermano Francisco Díaz del Ribero fue el arquitecto encargado de diseñar las escuelas en el sitio ya previsto por Martín de Baseta en 1597. No lo tuvo fácil pues, según la Historia del Colegio de San Pablo, sabemos que tuvo que sufrir los entrometimientos del padre rector Pedro de Fonseca, empeñado en introducir variaciones en el trazado de Díaz del Ribero, con tan mal resultado que los errores ocasionados ascendieron a siete mil ducados y provocaron un retraso considerable en la ejecución de las obras:

... tratándole con desprecio o condenándole algunas trazas, nunca mostró queja: callava como si no tuviera qué responder; pero por él respondían sus mismas obras. [...]. Y este colegio lo a padecido en la fábrica de las escuelas por aver un superior, que tenía muncha mano en ella por ser los fundadores sus hermanos, apartándose de la traza y disposición deste gran artífice y querido seguir el parezer de otros, aunque de muncha opinión ${ }^{29}$.

\footnotetext{
${ }^{26}$ Esta solución, según el padre Alonso de Ayala (1596-1680), hubiese sido incorrecta porque en Granada el espacio era menor y hubiese ocasionado una notable reducción en la iluminación de los aposentos, "que quedarían fríos y por eso inhabitables", además de arriesgar la estabilidad del edificio. Béthencourt/Olivares, 1991: 229.

27 El padre Pedro de Fonseca (1590-1667) convenció a sus dos hermanos, Íñigo y Juan, capellán del rey, y a sus dos hermanas, Catalina y Leonor, para que el único heredero de la familia, Martín de Fonseca (1609-1649), hijo de su hermana Catalina, entrara en la Compañía junto con todas las haciendas familiares, destinadas a la fundación de las escuelas. Béthencourt/Olivares, 1991: 246-247, 318-320.

${ }^{28}$ Montells y Nadal, 1870: 335-336.

29 Béthencourt/Olivares, 1991: 349-350.
} 

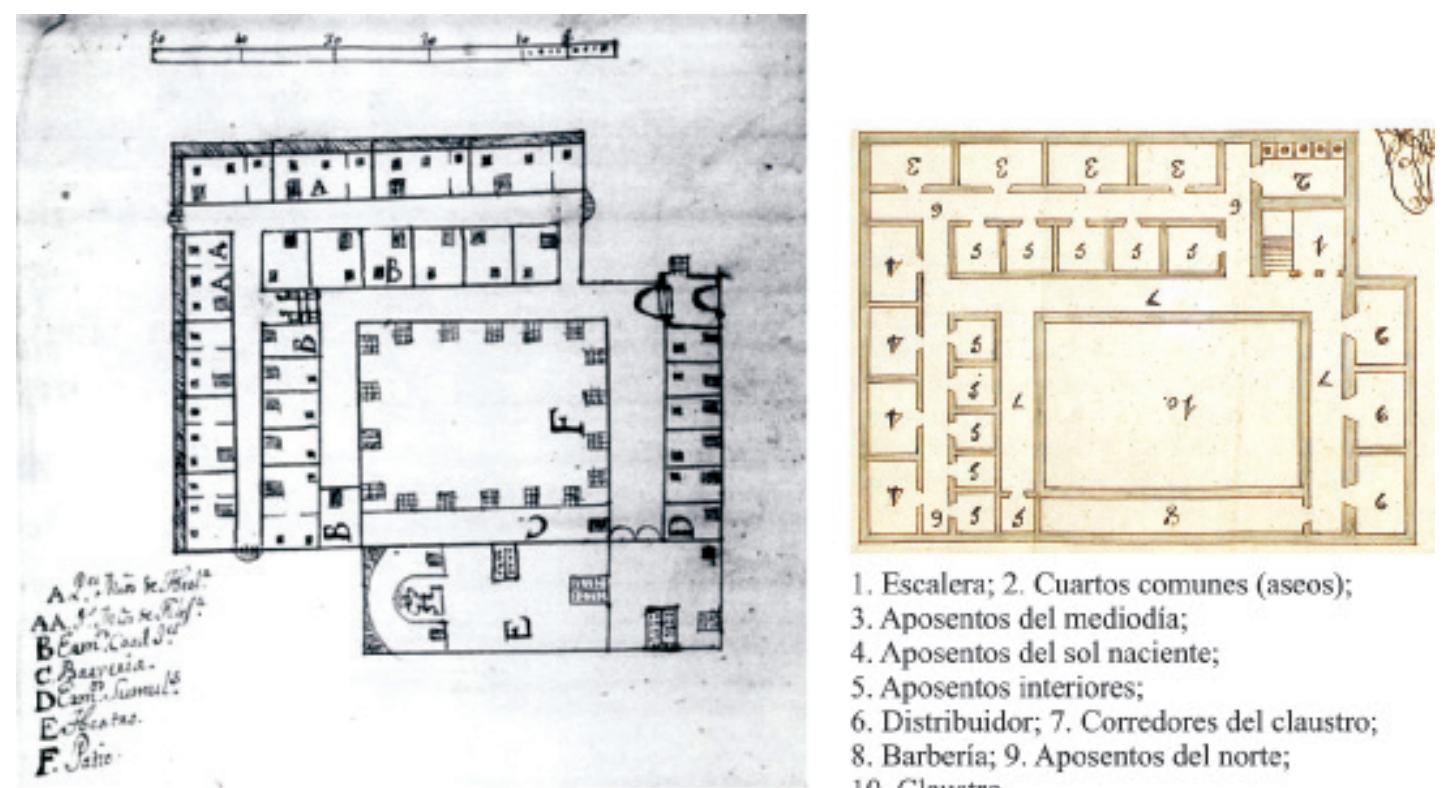

1. Escalera; 2. Cuartos comunes (aseos);

3. Aposentos del mediodia;

4. Aposentos del sol naciente;

5. Aposentos interiores;

6. Distribuidor; 7. Corredores del claustro;

8. Barbería; 9. Aposentos del norte;

10. Claustro.

Fig. 4. Planta alta de las escuelas del Colegio de San Pablo. Izq.: atribuida a Francisco Díaz del Ribero, hacia 1642. AHN, publicada sin pie de foto en Córdoba Salmerón, 2005. Der.: Juan José Fernández Bravo, Proyecto para el nuevo edificio de la Universidad, planta alta (girada $1800^{\circ}$ para establecer la comparativa), 1769. AHN.

De esta manera, estos superiores, sin duda el rector Pedro de Fonseca y el padre provincial Gonzalo de Peralta, dieron órdenes de que no se siguiese la traza del hermano Francisco Díaz del Ribero y así comenzaron las obras; lo que llevó a tener que exponer el caso ante el padre General, que otorgó la razón al hermano arquitecto. Hubo entonces que demoler partes ya ejecutadas, por no acomodarse al proyecto inicial de distribución de planta baja y alta. Aunque Rodríguez Gutiérrez de Ceballos afirma que la planta que trazó Ribero para las escuelas ya estaba perdida en $1691^{30}$, en la tesis de Córdoba Salmerón aparecen representadas en un dibujo a mano alzada, conservado en el AHN, sin fechar y atribuido erróneamente por Salmerón a Martín de Baseta $^{31}$. En mi opinión, podemos asignar sin duda la autoría de este croquis, que correspondería a la distribución de la planta alta de las escuelas, a Francisco Díaz del Ribero, pues era el hermano arquitecto que había recibido el encargo de su diseño (fig. 4 izq.). Los espacios se organizan alrededor del claustro, designado con la letra F. En el ángulo sureste quedan definidos los aposentos exteriores, con la letra A e interiores, con la B. Los situados al oeste, en la crujía común con la residencia jesuita, son nombrados con la $\mathrm{D}$; en esta misma ala se realiza la conexión entre la casa y las escuelas, a través de un vestíbulo con doble puerta. Díaz del Ribero dibuja también el teatro de conclusiones, letra E, y la portería o zaguán de acceso, por gozar ambos de doble altura. Notamos que falta por trazar la escalera de conexión entre los dos niveles del edificio. Las puertas y las ventanas de todas las estancias aparecen abatidas sobre el plano horizontal. Resulta muy interesante la correspondencia de espacios y huecos que hallamos al comparar este croquis con el plano de planta alta que realizó el maestro de obras Juan José Fernández Bravo (17061780) en 1769 para la adaptación de las escuelas a edificio universitario (fig. 4 der.).

Las obras de las escuelas continuaban ejecutándose hacia 1668, fecha en la que tenemos constancia del encargo de dieciséis columnas de Sierra Elvira para el patio, según diseño de

\footnotetext{
${ }^{30}$ Rodríguez Gutiérrez de Ceballos, 2004: 186.

31 Córdoba Salmerón, 2005: 90, 96. Esta planta, hasta entonces inédita, no es incluida en el libro fruto de su tesis. Córdoba Salmerón, 2006.
} 
Francisco Díaz del Ribero. A Gila Medina le surge el interrogante sobre la no coincidencia entre el número de columnas encargado y las que se colocaron en el patio, dieciocho. Las dos que faltaban, afirma este autor que podía ya haberlas tenido el patronato de los Fonseca o habérselas encargado a otros canteros ${ }^{32}$. En mi opinión, también cabe la posibilidad que fuesen utilizadas dos columnas que sobraban del patio de la residencia de los jesuitas, también llamado de los naranjos (véase fig. 6 sup.). Ribero no sólo trabajó como arquitecto, sino también en la ejecución material de los espacios principales: claustro, zaguán y teatro de actos públicos, aunque algunos no se finalizaron hasta después de su fallecimiento en 1670. Ejemplo de ello es la inauguración del teatro de las escuelas el 24 de octubre de 1672 con unas conclusiones generales de Teología ${ }^{33}$.

En 1694 se construyó un pabellón de planta baja y alta, destinado a dependencias de servicios, en la parte posterior del Colegio junto al estanque grande, "sacándose desde cimientos el edificio; fue obra de gran importancia y que se deseaba muchos años avía, porque los antiguos eran sobre indecentes de gran incomodidad y cortedad; tuvo de costa la obra hasta 4 mil ducados" ${ }^{\prime 34}$. Hacia 1698 se construyó un pasadizo para comunicar la iglesia del Colegio de San Pablo con el de San Bartolomé y Santiago, habiendo pedido permiso a la ciudad, dicho pasadizo atravesaba la calle de separación entre ambos colegios.

Todas las aulas de las escuelas fueron por fin inauguradas en septiembre de 1699, "cuando se empezaron los Estudios a 17 de dicho mes, acabadas las vacaciones y Exercicios de Maestros, se estrenaron las 7 clases nuevas de Teología, Artes y Gramática [...], cuia obra avía muchos años que se avía empezado; y por cuanto sólo se avían hecho dos clases para Filosofía" ${ }^{35}$. Al trasladarse las clases de Artes y Teología a las nuevas aulas, quedaron sin uso las antiguas situadas en la planta baja del cuarto viejo. Se determinó hacer en su lugar un cuarto doble de aposentos, de la misma manera que estaban los de la planta alta, destinada a los teólogos. Los nuevos locales servirían para el alojamiento, cuando fuese necesario, de los procuradores de Castilla, los administradores del mayorazgo de los Beneroso y otras personalidades relacionadas con obras pías. Los gastos del reacondicionamiento, que nos recuerda a la distribución inicial del padre Bustamante, ascendieron a 2.418 reales, finalizándose en diciembre de 1699.

En el mes de octubre de 1701 concluyeron las obras de la enfermería baja de verano, en el ala oeste de la residencia jesuita, y de la nueva librería, situada justo encima de aquélla, en planta alta. El refectorio, que pasó a ocupar el lugar antes destinado a capilla y teatro, en el ala sur del patio principal, fue reformado en 1707. Se colocaron azulejos y se adornaron los huecos con vidrieras.

Con la construcción de la portada barroca de las escuelas, entre 1715 y $1717^{36}$, se iba a ver por fin cumplida la voluntad de los fundadores, que deseaban fuese "magnífica" y estuviese dedicada a la Inmaculada Concepción, esculpida en una imagen atribuida a José Risueño, a imitación de las de Alonso Cano. La autoría de esta portada, toda de mármol, con columnas salomónicas en el primer cuerpo y en el segundo corresponde, casi con toda certeza, a Francisco Hurtado Izquierdo, quien ya había proyectado unas columnas iguales para las portadillas laterales del Sagrario de la Catedral, que posteriormente no fueron colocadas y en 1752 se instalan en la portada del Castillo de Bibataubín ${ }^{37}$. El uso de la columna salomónica se generalizó desde su empleo en el baldaquino de la Basílica de San Pedro en el Vaticano (1627-1632). En Granada, aparece por primera vez, ejecutada en madera, de la mano de Francisco Díaz del Ribero en el retablo mayor de la iglesia del Colegio de San Pablo.

32 Gila Medina, 1999: 429, según Archivo Notarial de Granada (ANGr), legajo 813, folios 819-821.

33 Béthencourt/Olivares, 1991: 377.

34 Béthencourt/Olivares, 1991: 412.

35 Béthencourt/Olivares, 1991: 424-425.

36 Rodríguez Gutiérrez de Ceballos, 1967: 186. Gila Medina, 1999: 433.

37 Hurtado Izquierdo llegó a Granada en 1704 para encargarse del nuevo Sagrario. Gómez Román, 1999: 448. Gallego Burín, 1987: 120. 

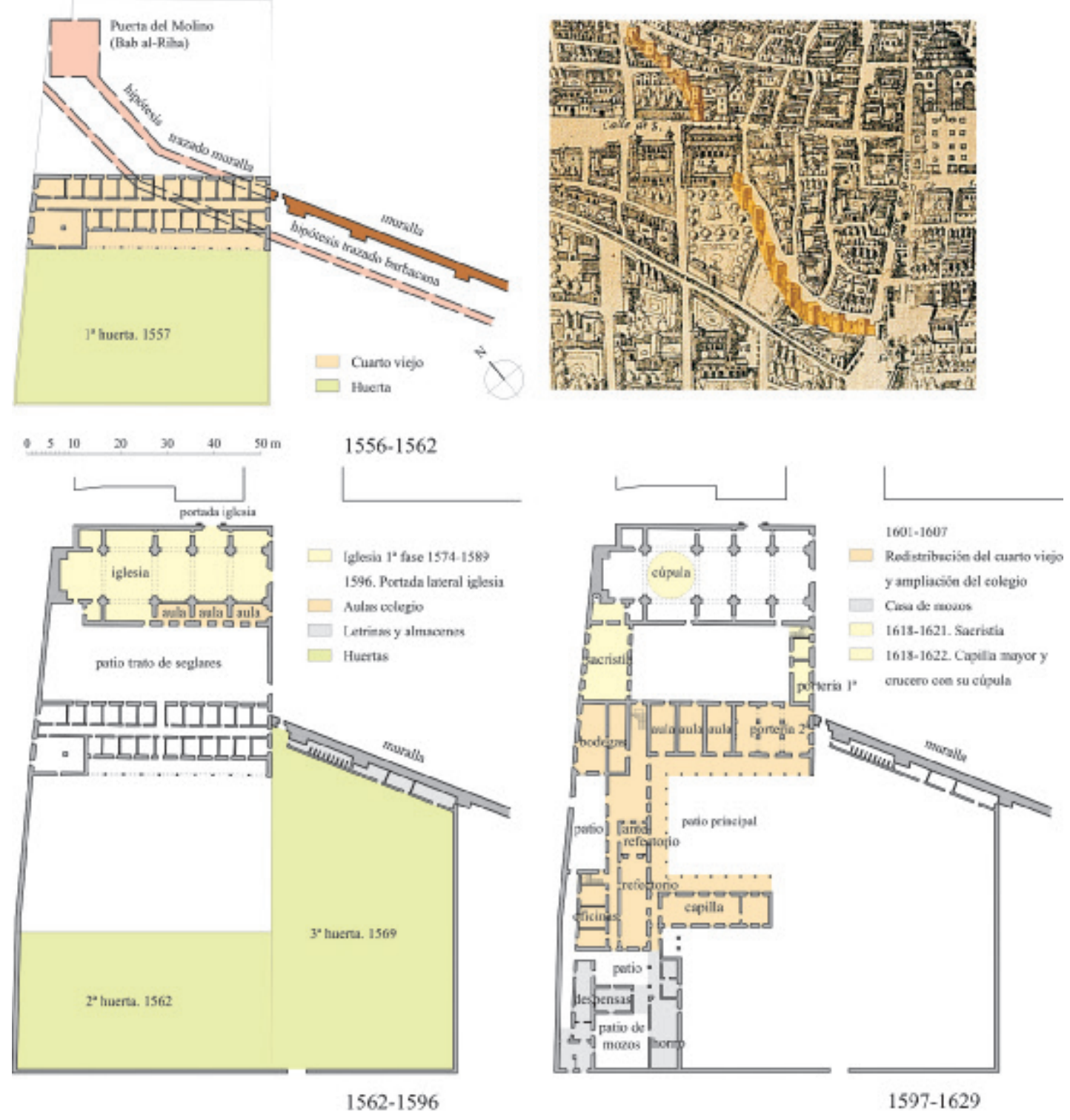

Fig. 5. El proceso constructivo del Colegio de San Pablo: 1556-1629. Sup. izq.: planta hipótetica del Colegio de San Pablo en 1562. Sup. der.: trazado de la muralla, destacada en Ambrosio de Vico, fragmento de la Plataforma de la ciudad de Granada, grabada en 1613. Inf. izq. y der.: plantas hipotéticas del Colegio de San Pablo en 1596 y 1629, respectivamente. Autora: María del Carmen Vílchez Lara.

\section{Etapas constructivas del Colegio de San Pablo a través de la planimetría}

El exhaustivo y ordenado análisis de las fuentes documentales existentes, tanto gráficas como escritas, sometidas a una atenta revisión crítica, además de la observación in situ y medición del estado actual del edificio, sede de la Facultad de Derecho, me ha permitido elaborar un preciso recorrido gráfico por las fases constructivas del Colegio de San Pablo (figs. 5, 6 y 7). Del edificio levantado por los jesuitas entre 1556 y 1767, año de su expulsión, tal y como hemos podido comprobar, sólo se conservan en el AHN dos planos históricos de propuestas de distri- 


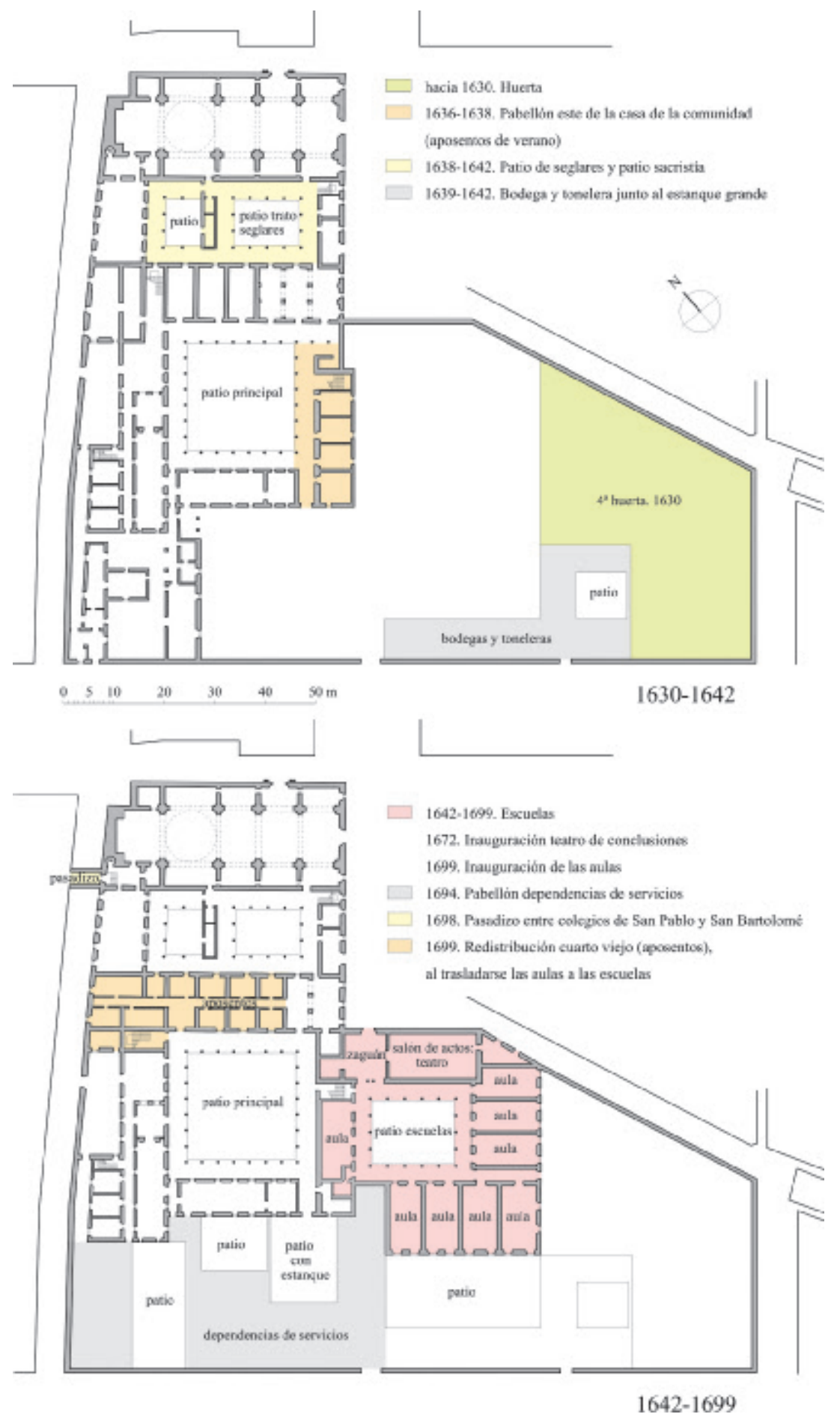

Fig. 6. El proceso constructivo del Colegio de San Pablo: $1630-1699$. Sup. e inf:: plantas hipotéticas del Colegio de San Pablo en 1642 y 1699 , respectivamente. Autora: María del Carmen Vílchez Lara.

buciones de planta baja, la de Giuseppe Valeriani de 1579 y la de Martín de Baseta de 1597, junto con el croquis de planta alta de las escuelas, que no había sido fechado ni atribuido correctamente su autoría, antes de la presente investigación. Se hacía por tanto imprescindible el levantamiento de una planimetría que estudiara la progresiva construcción de las edificaciones 
Fig. 7. El proceso constructivo del Colegio de San Pablo: 1700-1767. Sup. e inf.: plantas hipotéticas del Colegio de San Pablo en 1740 y 1767 , respectivamente. En el plano de 1767 he indicado los usos de los espacios de planta baja, justo antes de la expulsión jesuita.

Autora: María del Carmen Vílchez Lara.

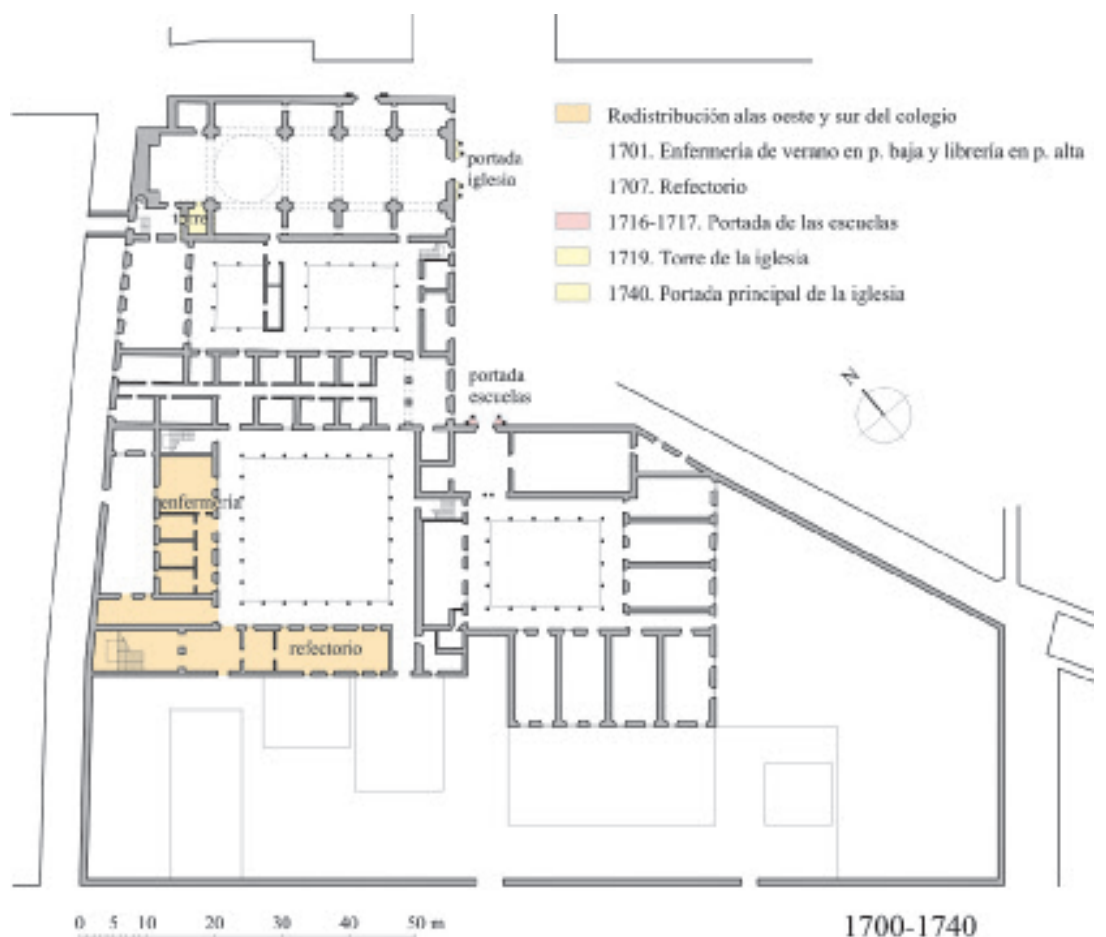

$1700-1740$

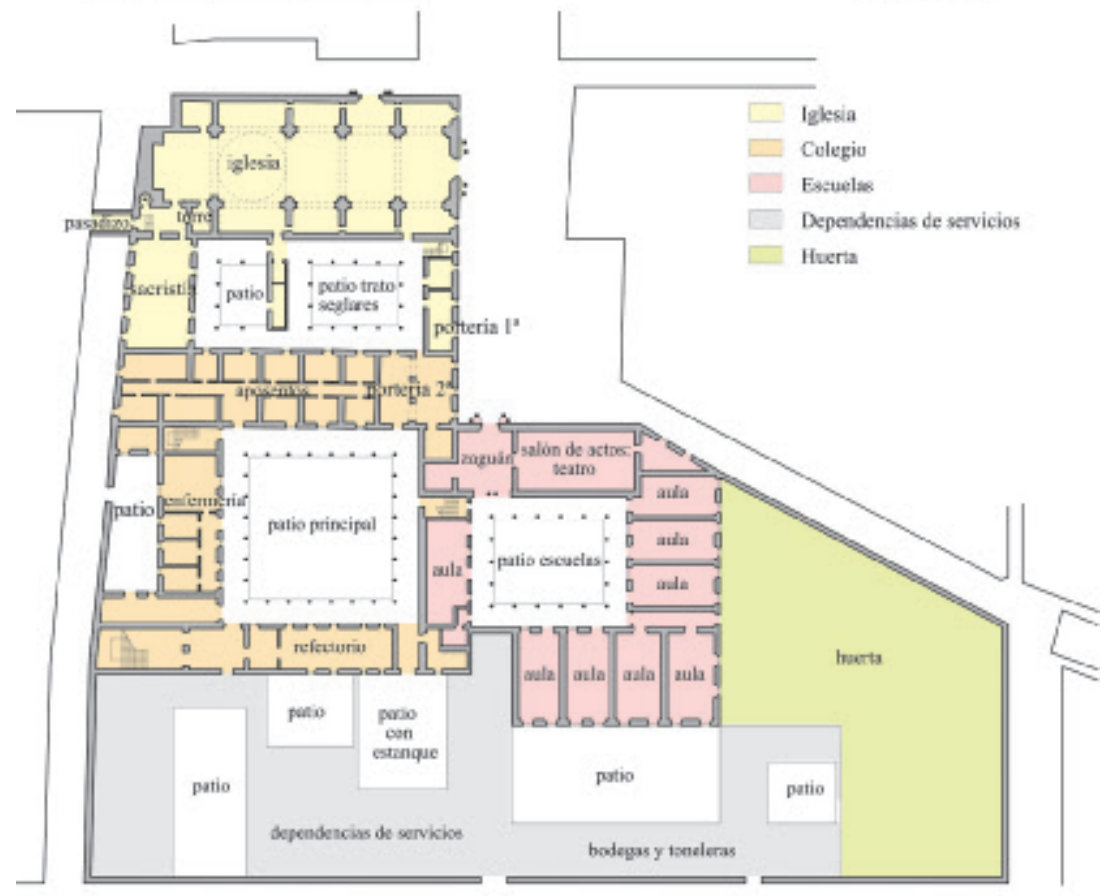

1767

que fueron configurando el complejo jesuita, fundamental a su vez para analizar el variable uso de los espacios durante el Antiguo Régimen. De la documentación gráfica histórica analizada y utilizada para la elaboración de la planimetría, destaca, por su exactitud en las medidas, la del proyecto de ampliación y reforma de la Universidad de Santiago Baglietto de 1871 y la del 
proyecto de ampliación de aulas de Domingo Lois Monteagudo de $1777^{38}$. También he tenido en cuenta los mencionados planos del Colegio de Giuseppe Valeriani y Martín de Baseta, junto con los proyectos de adaptación a Universidad y colegios de Juan José Fernández Bravo de 1769, el plano de la Universidad de Juan Pugnaire de 1831 y, por supuesto, el estado actual de la edificación, muy transformada, pero de gran utilidad en cuanto a medidas generales y de espacios que no han sufrido apenas variación; sin olvidar toda la información extraída de las fuentes escritas.

\section{Traslado de la Universidad a las Escuelas del Colegio de San Pablo}

\section{Expulsión de los jesuitas: la incautación de sus colegios}

La supresión de la Compañía de Jesús en España fue el resultado final de los enfrentamientos que mantuvieron los jesuitas con los regalistas e ilustrados, que apoyaban la corona de Carlos III y sus políticas de reformas en el plano teológico y educativo ${ }^{39}$. Entre las disputas teológicas destacaban las críticas jesuíticas contra el jansenismo y la relajación moral de muchos frailes; mientras que a nivel educativo, el beneficio obtenido con la exclaustración y enajenación de los bienes de la Compañía, permitiría a la monarquía convertir sus colegios en universidades públicas, residencias de estudiantes y facultades de Teología. El motín de Esquilache, acontecido en 1766, fue la excusa perfecta para que el gobierno justificara la supresión de la Compañía de Jesús, con la consiguiente incautación de todos sus bienes. Los jesuitas fueron acusados de instigar el citado motín, movimiento social espontáneo, cuya causa principal hay que buscarla en la subida de precios de productos básicos como el pan. Sofocado el motín y decretada la expulsión el 3 de abril de 1767, los jesuitas resultaron perdedores y, acusados de la revuelta, se vieron obligados a abandonar sus domicilios. Montells y $\mathrm{Nadal}^{40}$ en su Historia del Origen y Fundación de la Universidad de Granada (1870) defiende con fervor la expulsión de los jesuitas, ya que las Universidades de varias ciudades españolas, entre ellas la granadina, se vieron directamente beneficiadas. Se convertirían en las herederas de una estructura física muy bien consolidada en los cascos urbanos: los colegios incautados a la Compañía de Jesús.

Un acontecimiento extraordinario acababa de tener lugar en nuestra España. La Compañía de Jesús, los hijos de Loyola, cuyo inmenso poder y riquezas les colocaba á gran altura, ejerciendo una influencia poderosa y eficaz en el ánimo de los Monarcas por medio de los confesores, que muchas veces pertenecian á esta Congregacion, habian sido arrojados de Portugal y expulsados de Francia. Á ellos les fueron atribuidos los desórdenes que el año anterior habian comprometido la corona de Carlos III; á ellos se les hacia cómplices de perturbaciones y escándalos que el Monarca no podia mirar con indiferente desden; á ellos se les señalaba, no sin justicia, el propagar y sostener doctrinas antimonárquicas, así es, que tomando en consideracion las quejas que se denunciaban por medio de varios escritos, no titubeó en adoptar una resolucion extrema, expulsando y extrañando de todos los dominios Españoles á los padres de la Compañía de Jesús en la noche del 31 de Marzo al 1. ${ }^{\circ}$ de Abril de 1767 en Madrid, y en la del 2 á 3 de Abril en los demas puntos del reino ${ }^{41}$.

38 Proyecto de ampliación y reforma de la Universidad de Granada agregándole lo que fue Cuartel de la Compañia, 1871, Archivo General de la Administración, Alcalá de Henares (AGA), caja 31/8049, legajo 8839-9. Construcción de ocho aulas propuestas por Pedro Joseph Valiente al Consejo de Castilla, 1775-1777, AHN, Consejos, legajo 5446, n. ${ }^{\circ} 18$ bis.

39 Batllori, 1988. Ferrer Benimeli, 1989. Barrios Rozúa, 1998: 75-77.

40 Francisco de Paula Montells y Nadal (1813-1893) fue rector de la Universidad granadina entre 1868 y 1872. Liberal, a favor de "la Gloriosa", formó parte de la junta revolucionaria de Granada. López, 2006: 108.

41 Montells y Nadal, 1870: 278-279. 
Una vez expulsados los jesuitas de su antiguo y céntrico Colegio de San Pablo en 1767, la Universidad granadina se instala en él dos años más tarde, aunque debe compartirlo en principio con varios colegios y desde 1802, tras el desalojo del Colegio de Santa Cruz, con el Cuartel de la Compañía, ocupado por la Administración Militar hasta 1871. La Universidad contará desde el principio con el incondicional apoyo de Pedro José Pérez Valiente, miembro del Consejo de Castilla, en cuya carta emitida el 6 de septiembre de 1768 ordenaba el traslado de la misma y de tres colegios al antiguo Colegio de San Pablo:

... se ha dignado S.M. resolver que [...] se proceda [...] á la traslación material de la Universidad y del Colegio de Santa Cruz á la casa que fue de los jesuitas, trasladándose asimismo á ella, pues lo permite la extension del edificio, el Real Colegio de Santa Catalina y el Imperial de San Miguel con la separación y en la forma que lo propongan los Sres. Arzobispo é intendente de esa Ciudad $^{42}$.

Es indudable que, pese a las buenas intenciones del consejero de Castilla, fue un grave error conceder a la Universidad tan limitado espacio físico, pues casi desde el principio se le queda pequeño su nuevo edificio, compuesto principalmente por ocho aulas y un teatro para conclusiones, en planta baja, organizados en torno a un patio central, y por biblioteca, secretaría, rectorado, archivo y cuarto de bedeles en planta alta. Sin duda, no se tuvo en cuenta, entre otras cosas, que la Universidad absorbería gran parte de los estudiantes que se formaban en las escuelas jesuitas.

\section{La reorganización de espacios del Colegio de San Pablo: los planos de Juan José Fernández Bravo}

El maestro de obras encargado de redactar el proyecto de instalación de la Universidad y tres colegios en el antiguo complejo jesuita fue Juan José Fernández Bravo, en el cual incluyó tres planos. El primero muestra la distribución de espacios del estado actual en que se encontraba el Colegio de San Pablo, introduciendo como modificación principal la exigida como primer objetivo para la instalación de la Universidad en el edificio de las escuelas: incomunicarla con los tres colegios que debían trasladarse también al inmueble. El trazado de este plano es esquemático e impreciso, con fallos generales en las proporciones, disposición y medidas de los espacios. Tampoco se han representado los huecos de ventanas en las fachadas (fig. 8 sup.). El aislamiento de la Universidad se materializó mediante el levantamiento de un muro en el ala sureste del patio principal, pasando dicha crujía a pertenecer a la Universidad. Se proyectó una escalera frente a la puerta principal, en un patinillo existente, para acceder al primer piso, donde quedaría emplazada la biblioteca, junto a la sala de actos secretos, rectorado, secretaría, cuarto de bedeles y archivo ${ }^{43}$. También se preveía, en la memoria del proyecto, la construcción de otra escalera que arrancara desde el zaguán de las escuelas, antes de llegar al patio. Sin embargo, es de extrañar que esta escalera no aparezca dibujada en ninguno de los planos del proyecto.

El segundo plano incorporado por Fernández Bravo corresponde a los pisos bajo y alto de las escuelas. Hay que advertir que el sentido de la lectura de la planta baja está orientado según el acceso desde la calle; sin embargo, sin ningún motivo aparente, nos encontramos que la planta alta está girada $180 .^{\circ}$ respecto de la baja. En estos planos, observamos la incomunicación de la Universidad con el resto del edificio y la escalera proyectada frente a la puerta de entrada. La distribución de los antiguos aposentos jesuitas de planta alta no sufre modificación alguna. En el

\footnotetext{
42 El intendente, Ignacio Bermúdez de Castro, utilizó el 30 de septiembre la Real Orden del Consejo de Castilla para incautarse del excolegio jesuita. Montells y Nadal, 1870: 299-300.

43 Sobre aplicación del colegio y botica que fue de regulares, 1767-1769, AHN, Consejos, legajo 15860, n. ${ }^{\circ} 2-5$.
} 


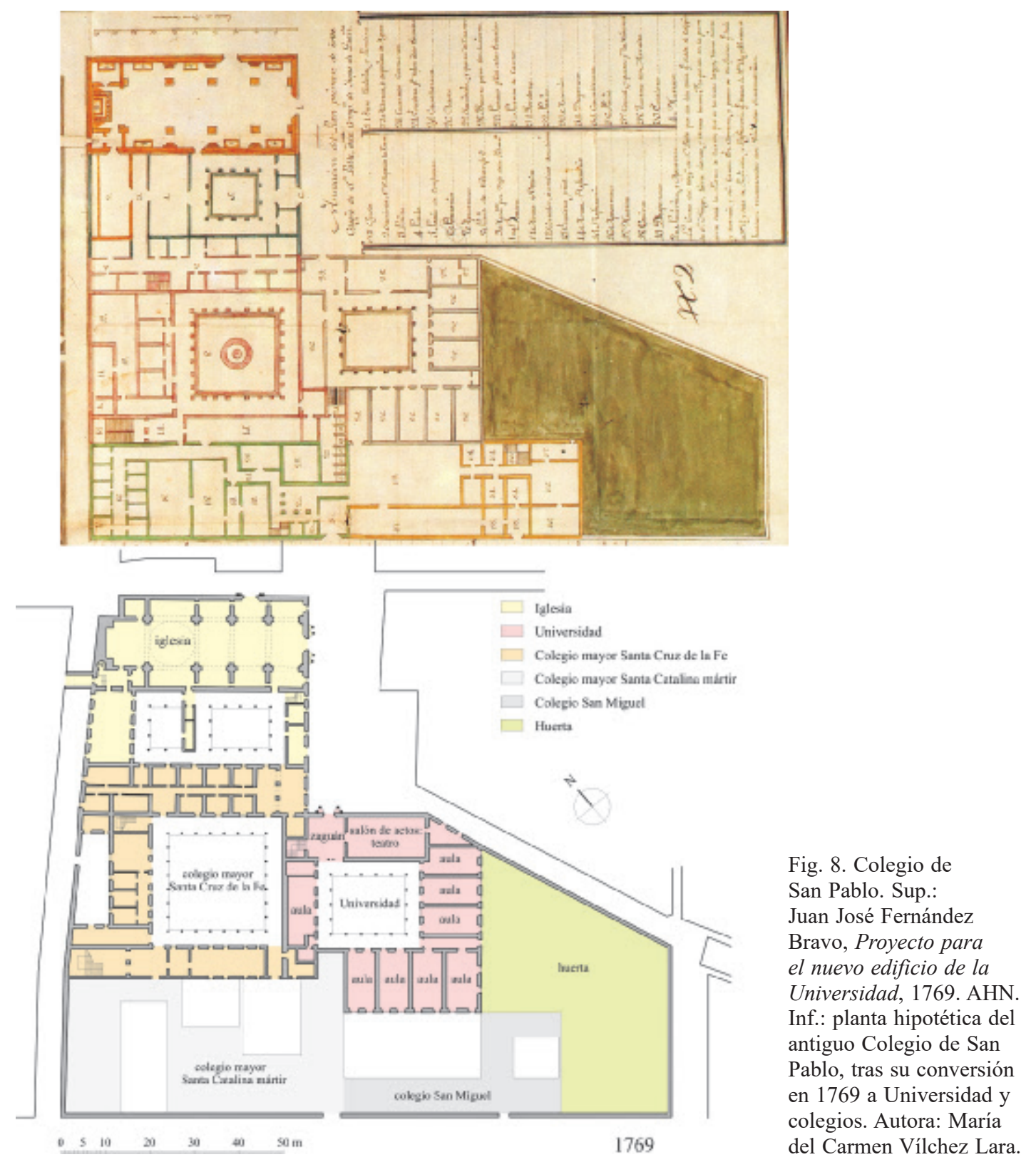

tercer plano aparecen distribuidos, e indicados por colores, los tres colegios que ocuparían el resto del antiguo Colegio de San Pablo.

El traslado de la Universidad a las antiguas escuelas jesuitas tuvo lugar el 29 de marzo de $1769^{44}$. La descripción del edificio universitario que el claustro granadino realizó como respuesta a la orden estatal recibida el 23 de febrero de $1770^{45}$, previa a la reforma de estudios universitarios promovida por Carlos III, en la que se solicitaba información de las enseñanzas imparti-

44 Fernández Carrión, 1997: 85-88.

45 Fernández Carrión, 1997: 89. 
das y los medios con que se contaba, es aclaratoria de las obras que finalmente se habían llevado a cabo en el edificio. Principalmente consistieron en la incomunicación de las dependencias universitarias con respecto al resto de colegios, la ejecución de la escalera situada en el zaguán, quedando el patinillo del ángulo suroeste sin tocar, y por tanto, sin construir la gran escalera principal proyectada por Fernández Bravo frente a la puerta de entrada (fig. 8 inf.), la previsión de un gran local para biblioteca en planta alta, aún sin terminar, la sala de celebración de claustros y las viviendas de los bedeles.

\section{Conclusiones}

El Colegio de San Pablo en Granada carecía de una documentación gráfica, que ayudase a comprender el complejo proceso constructivo y la historia de una arquitectura que se fue levantando conforme las posibilidades económicas de los jesuitas lo iban permitiendo: en unas ocasiones debidas a las buenas cosechas y en otras, las más decisivas, a las donaciones de sus benefactores, entre las que destaca la de la familia Fonseca, que posibilitó la construcción de las escuelas del Colegio.

Esta investigación se ha centrado principalmente en el análisis histórico-constructivo de la residencia jesuita, a partir del cuarto viejo, germen del Colegio de San Pablo, estudiando todas sus transformaciones y la construcción de las escuelas, como futuro emplazamiento de la Universidad granadina. La evolución constructiva de la iglesia se ha tenido en cuenta para el levantamiento de los planos, aunque no se ha desarrollado con la misma amplitud que el colegio y las escuelas, al no ser objeto de este estudio y existir en la actualidad numerosas y solventes publicaciones sobre la misma ${ }^{46}$.

En este trabajo se ha podido datar y atribuir a Francisco Díaz del Ribero el tercer plano histórico conservado en el AHN, correspondiente a la planta alta de las escuelas.

La lectura de la planimetría elaborada para este artículo facilita el entendimiento del levantamiento cronológico del Colegio y permite establecer comparativas con los escasos planos históricos incluidos en los proyectos que sobre el Colegio de San Pablo se conservan.

\section{BIBLIOGRAFÍA}

Acale Sánchez, Fernando (2005): Plazas y paseos de Granada: de la remodelación cristiana de los espacios musulmanes a los proyectos de jardines en el ochocientos. Granada: Universidad de Granada.

Barrios Rozúa, Juan Manuel (1998): Reforma Urbana y Destrucción del Patrimonio Histórico de Granada. Ciudad y Desamortización. Granada: Universidad de Granada.

Barrios Rozúa, Juan Manuel (2004): "La sacralización del espacio urbano: los conventos. Arquitectura e historia". En: Barrios Aguilera, Manuel/Galán Sánchez, Ángel (eds.): La historia del Reino de Granada a debate. Viejos y nuevos temas. Perspectivas de estudio. Málaga: Diputación Provincial de Málaga, pp. 627-652.

Barrios Rozúa, Juan Manuel (2006): Guía de la Granada desaparecida. Granada: Comares.

Barrios Rozúa, Juan Manuel (2014): “Arquitectura y enseñanza: los jesuitas en Granada”. En: Martínez Medina, Francisco Javier (ed.): La huella de los jesuitas en Granada: del Colegio de San Pablo a la Facultad de Teología. Granada: Facultad de Teología de Granada, pp. 209-242.

Batllori, Miguel (1988): "La expulsión de los jesuitas y el jurisdiccionalismo antirromano: raíces napolitanas y austracistas”. En: Carlos III y la Ilustración. Madrid: Ministerio de Cultura, pp. 235-246.

Béthencourt, Joaquín de/Olivares, Estanislao (1991): Historia del Colegio de San Pablo, Granada, 1554-1765. Archivo Histórico Nacional, Madrid, Ms. Jesuitas, Libro 773. Granada: Facultad de Teología.

Calatrava Escobar, Juan/Ruiz Morales, Mario (2005): Los planos de Granada 1500-1909: cartografia urbana e imagen de la ciudad. Granada: Diputación Provincial de Granada.

Córdoba Salmerón, Miguel (2005): Patrimonio artístico y ciudad moderna. El conjunto Jesuítico y Colegio de San Pablo entre los siglos XVI y XVIII. Granada: Universidad de Granada.

46 Entre ellas Rodríguez Gutiérrez de Ceballos, 1967; 2004. Gómez-Moreno Calera, 1989. Córdoba Salmerón, $2005 ; 2006$. 
Córdoba Salmerón, Miguel (2006): El Colegio de la Compañía de Jesús en Granada: arte, historia y devoción. Granada: Universidad de Granada.

Fernández Carrión, Mercedes (1997): "La Ilustración y la reforma universitaria". En Henares Cuéllar, Ignacio/López Guzmán, Rafael (eds.): Universidad y Ciudad. La Universidad en la Historia y la Cultura de Granada; 2. ${ }^{a}$ ed.; Granada: Universidad de Granada, pp. 75-98.

Ferrer Benimeli, José Antonio (1989): "Carlos III y la extinción de los jesuitas". En: Actas del Congreso Internacional sobre Carlos III y la Ilustración. Madrid: Ministerio de Cultura, pp. 239-259.

Gallego Burín, Antonio (1987): El barroco granadino. Granada: Comares.

Gila Medina, Lázaro (1999): "Contribución al estudio del antiguo colegio de San Pablo de los Jesuítas -hoy facultad de derecho-de Granada”. En: Cortés Peña, Antonio Luis/López-Guadalupe Muñoz, Miguel Luis (eds.): Estudios sobre Iglesia y sociedad en Andalucía en la edad moderna. Granada: Universidad de Granada, pp. 425-444.

Gila Medina, Lázaro (2015): "Patrimonio artístico y vida conventual: propuesta museística para el monasterio de la Encarnación de Granada". Quiroga: Revista de Patrimonio Iberoamericano, 7, pp. 32-44.

Gómez Román, Ana María (1999): "Promoción y mecenazgo artístico del Arzobispado de Granada durante el siglo XVIII”. En: Cortés Peña, Antonio Luis/López-Guadalupe Muñoz, Miguel Luis (eds.): Estudios sobre Iglesia y sociedad en Andalucía en la edad moderna. Granada: Universidad de Granada, pp. 445-461.

Gómez-Moreno Calera, José Manuel (1989): La Arquitectura religiosa granadina en la crisis del Renacimiento (15601650): Diócesis de Granada y Guadix-Baza. Granada: Universidad de Granada.

Gómez-Moreno González, Manuel (1998): Guía de Granada (facsímil, 1892. Granada. Imprenta de Indalecio Ventura. Estudio preliminar José Manuel Gómez-Moreno Calera ed.). Granada: Universidad de Granada.

Kagan, Richard L. (dir.) (1986): Ciudades del Siglo de Oro. Las vistas españolas de Anton van den Wyngaerde. Madrid: El Viso.

López, Miguel Ángel (2006): Los rectores y cancilleres de la Universidad de Granada: 1532-2004. Granada: Universidad de Granada.

Martínez Medina, Francisco Javier (2001): "Fray Hernando de Talavera, primer alcalde de Granada: Religión y Municipio en la Granada Moderna". En: del Cerro Bex, Victoriano/Moreno Garzón, Luis/Parra Arcas, María Dolores (coords.): Granada: su transformación en el siglo XVI. Conferencias pronunciadas con motivo de la conmemoración del V. ${ }^{\circ}$ Centenario del Ayuntamiento de Granada. Granada: Ayuntamiento de Granada, pp. 63-85.

Montells y Nadal, Francisco de Paula (1870): Historia del Origen y Fundación de la Universidad de Granada. Granada: Imprenta de D. Indalecio Ventura.

Navarro Catalán, David Miguel (2012): Arquitectura jesuita en el Reino de Valencia (1544-1767). Valencia: Universitat Politècnica de València.

Olivares, Estanislao (1990): La docencia de filosofia y teología en el Colegio de San Pablo de Granada (1558-1767): discurso leído en la solemne apertura del curso académico 1989-1990 en la Facultad de Teología de Granada. Granada: Facultad de Teología.

Orihuela Uzal, Antonio (2001): "Las murallas de Granada en la iconografía próxima al año 1500". En: del Cerro Bex, Victoriano/Moreno Garzón, Luis/Parra Arcas, María Dolores (coords.): Granada: su transformación en el siglo XVI. Conferencias pronunciadas con motivo de la conmemoración del $V^{\circ}$ Centenario del Ayuntamiento de Granada. Granada: Ayuntamiento de Granada, pp. 103-134.

Patetta, Luciano/Coscarella, Cristiana/Zocchi, Daniella/Balestreri, Isabella (1990): L'architettura della Compagnia di Gesù in Italia XVI-XVIII secolo. Brescia: Grafo edizioni.

Ramírez Molina, María de Tíscar (2012): “Análisis estructural de la cúpula de la iglesia de los Santos Justo y Pastor de Granada". En: http://hdl.handle.net/10481/25144.

Rodríguez Gutiérrez de Ceballos, Alfonso (1967): Bartolomé de Bustamante y los orígenes de la arquitectura jesuítica en España. Roma: Institutum Historicum.

Rodríguez Gutiérrez de Ceballos, Alfonso (2004): “Arquitectura y arquitectos en la provincia jesuítica de Andalucía”. En: García Gutiérrez, Fernando (coord.): El arte de la Compañía de Jesús en Andalucía: 1554-2004. Córdoba: Cajasur, pp. 57-134.

Vallery-Radot, Jean/Lamalle, Edmond (1960): Le recueil de plans d'édifices de la Compagnie de Jésus conservé a la Bibliothèque Nationale de Paris. Roma: Institutum Historicum.

Wittkower, Rudolf/Jaffe, Irma B. (1992): Architettura e arte dei gesuiti. Milán: Electa.

Fecha de Recepción: 3-VIII-2016

Fecha de aceptación: 15-II-2017 